\title{
ISOLASI MIKROORGANISME ANAEROB LIMBAH CAIR TEKSTIL MENGGUNAKAN DESIKATOR SEBAGAI INKUBATOR ANAEROBIK
}

\author{
Dianty Rosirda Dewi Kurnia, Ira Permatasari, Yuni Rafika \\ Teknik Kimia-Politeknik Negeri Bandung \\ Jl.Terusan Gegerkalong Hilir, Ds.Ciwaruga, Kabupaten Bandung 40012 \\ Telp./Fax. (022) 2013789/(022) 2016403 \\ e-mail:diantyrosirda@gmail.com
}

\begin{abstract}
Abstrak: Isolasi Mikroorganisme Anaerob Limbah Cair Tekstil Menggunakan Desikator Sebagai Inkubator Anaerobik. Penggunaan mikroorganisme untuk mengolah limbah cair tekstil yang mengandung bahan organik tinggi sangat potensial untuk dikembangkan. Mikroorganisme anaerob dapat digunakan pada pengolahan limbah cair, yaitu untuk mendegradasi senyawasenyawa organik kompleks berantai panjang menjadi senyawa yang lebih sederhana sehingga dapat menurunkan beban kerja dari pengolahan aerobik. Penelitian ini bertujuan untuk mengetahui efektivitas desikator termodifikasi sebagai inkubator anaerob dan melakukan isolasi mikroba dari unit pengolahan air limbah tekstil sehingga diperoleh konsorsium mikroorganisme (mixed culture) anaerobik. Desikator dimodifikasi dengan dialiri gas nitrogen untuk menghilangkan gas oksigen di dalam desikator. Parameter yang digunakan sebagai indikator adalah pengamatan secara makroskopis, mikroskopis dan uji pembentukan hidrogen sulfida. Isolat pembanding yang digunakan adalah Pseudomonas aeruginosa sebagai bakteri aerob obligat, Escherichia coli sebagai bakteri anaerob fakultatif, Desulvofibrio desulfuricans dan Methanobrevibacter ruminantium sebagai anaerob obligat. Desikator termodifikasi juga digunakan sebagai inkubator untuk melakukan isolasi. Hasil penelitian menunjukkan bahwa desikator yang dimodifikasi mempunyai efektivitas sebagai inkubator anaerob meskipun bakteri obligat aerob dan aerob fakultatif masih dapat tumbuh karena pada media yang digunakan masih terdapat oksigen terlarut yang ditandai dengan warna pink di bagian atas media dan lilin dinyalakan di dalam desikator dapat juga digunakan sebagai indikator keberadaan oksigen. Desikator ini juga menunjukkan efektivitas untuk digunakan sebagai inkubator anaerob. Pada proses isolasi dari pengolahan limbah anaerob pabrik tekstil diperoleh 6 jenis isolat yang dapat digunakan sebagai konsorsium mikroorganisme (mixed culture) anaerobik.
\end{abstract}

\section{Kata kunci : Air limbah tekstil, desikator, inkubator anaerob, isolasi mikroorganisme}

\section{PENDAHULUAN}

Industri tekstil merupakan salah satu industri yang menghasilkan limbah cair yang berbeda karakteristik sesuai tahapan proses produksinya yang berbeda-beda. Secara umum, air limbah tekstil mengandung sejumlah senyawa organik baik yang mudah maupun yang sulit terdegradasi (nonbiodegradable) secara biologis.

Menurut Sastrawidana (2009), air limbah tekstil mempunyai karakteristik intensitas warna berkisar 50-2500 skala Pt-Co, COD $150-12000 \mathrm{mg} / \mathrm{L}$ dan BOD 80-6000 mg/L. Kandungan bahan organik yang tinggi terkait dengan bahan-bahan yang digunakan dalam industri tekstil seperti enzim, detergen, zat warna dan bahan-bahan tambahan lainnya. Parameter COD dan BOD yang dimiliki air limbah tekstil berada di atas baku mutu berdasarkan surat Keputusan Gubernur Jawa Barat No. 6 Tahun 1999 dimana kadar maksimum BOD adalah $85 \mathrm{mg} / \mathrm{L}$ dan COD $250 \mathrm{mg} / \mathrm{L}$.

Pengolahan air limbah secara anaerobik menjadi pilihan karena efektif dalam menanggulangi limbah dengan kandungan COD tinggi dan juga menghasilkan biogas yang dapat digunakan sebagai sumber energi. 
Selain itu, pengolahan anaerobik tidak memerlukan energi untuk aerasi dan kuantitas lumpur yang rendah serta bebas bau merupakan kelebihan lain dari sistem pengolahan secara anaerobik (Maynell, 1976 dalam Bagus, 2008).

Penggunaan mikroorganisme untuk mengolah air limbah yang banyak mengandung bahan organik tinggi sangat potensial untuk dikembangkan. Air limbah tersebut dapat dimanfaatkan secara langsung maupun tidak langsung oleh mikroorganisme sebagai nutrisi untuk pertumbuhannya. Pengolahan menggunakan mikroorganisme dapat dilakukan baik secara aerob maupun anaerob

Pengolahan secara anaerob dilakukan menggunakan mikroorganisme tanpa melibatkan oksigen bebas sebagai oksidan (penerima elektron) dalam proses respirasinya, tetapi menggunakan senyawa anorganik lain seperti sulfat dan nitrat. Mikroorganisme anaerob sensitif terhadap oksigen, karena dapat menghambat pertumbuhan dan menyebabkan kematian (Fardiaz, 1992).

Mikroorganisme anaerob dapat digunakan pada pengolahan air limbah, yaitu untuk mendegradasi senyawa-senyawa organik kompleks berantai panjang menjadi senyawa yang lebih sederhana sehingga dapat menurunkan beban kerja dari pengolahan aerobik (Frowen, 1992). Dalam hal ini terjadi stabilisasi material organik dengan cara mengkonversinya menjadi metana (CH4) dan produk anorganik lain termasuk CO2 (Kiely, 1998).

Salah satu cara yang biasa digunakan untuk isolasi mikroba anaerob adalah metode Hungate. Pada umumnya laboratorium mikrobiologi melakukan hal ini menggunakan Anaerobik jar. Peralatan ini kedap udara dan rendah oksigen karena ditambahkan paladium yang sangat efektif untuk mereduksi oksigen, namun harganya mahal. Humaidah (2011) menunjukkan bahwa desikator vakum memiliki potensi sebagai inkubator anaerob. Pada inkubator ini, mikroorganisme obligat aerob dan anaerob fakultatif masih dapat hidup yang diduga karena masih terdapat oksigen pada head space pada peralatan tersebut.

Penelitian ini ditujukan untuk mengetahui efektivitas desikator termodifikasi sebagai inkubator anaerob dan melakukan isolasi mikroba dari unit pengolahan air limbah tekstil sehingga diperoleh konsorsium mikroorganisme (mixed culture) anaerobik.

\section{METODE}

\section{Tahap Persiapan}

Sumber mikroorganisme diambil dari IPAL pabrik tekstil unit anaerob di Leuwigajah Kota Cimahi. Isolat pembanding, yaitu Pseudomonas aeruginosa sebagai bakteri aerob obligat dan Escherichia coli sebagai bakteri anaerob fakultatif diperoleh dari Laboratorium Mikrobiologi Departemen Teknik Kimia ITB, sedangkan bakteri Desulvofibrio desulfuricans dan Methanobrevibacter ruminantium sebagai bakteri anaerobik obligat diperoleh dari Laboratorium Mikrobiologi Universitas Airlangga Surabaya.

Pengembangbiakan mikroorganisme yang bersifat strict anaerob (obligat anaerob) dilakukan menggunakan metoda Hungate. Medium yang digunakan adalah thioglikolat dengan menambahkan MgSO4. $7 \mathrm{H} 2 \mathrm{O}$ sebagai elektron akseptor dan sodium laktat sebagai elektron donor (Humaidah, 2011)

Percobaan dilakukan untuk mengetahui efektivitas desikator termodifikasi, dimana pada desikator yang digunakan sebagai inkubator anaerob dialirkan gas nitrogen untuk menghilangkan gas oksigen yang ada di dalamnya. Desikator tersebut dilengkapi dengan silika gel sebagai bahan pengering. Bagian wadah dan tutup desikator diolesi dengan vaselin sehingga tidak 
memungkinkan udara untuk masuk.

Sebagai pembanding, dilakukan teknik Hungate, dimana isolat dalam tabung reaksi dialiri gas nitrogen. Tabung reaksi tersebut kemudian disimpan diatas meja kerja Kontrol positif yang digunakan adalah isolat bakteri yang diinokulasi tanpa perlakuan.

Tahap Percobaan Desikator sebagai inkubator anaerobik dan Isolasi Mikroorganisme

Tahap percobaan desikator sebagai inkubator anaerobik dilakukan menggunakan 4 isolat yang diletakkan di dalam desikator, teknik Hungate pada tabung reaksi dan yang diletakkan di meja kerja tanpa perlakuan.

a) Desikator sebagai inkubator anaerobik Tabung reaksi yang berisi media thioglikolat disterilisasi selama 15 menit pada suhu $121 \mathrm{oC}$ dengan tekanan 1,5 atm. Isolat diinokulasikan ke dalam media. (Humaidah, 2011).

Tabung reaksi yang berisi biakan kemudian diletakkan ke dalam desikator yang ditutup rapat dan dialirkan gas nitrogen untuk mengeluarkan gas yang ada di dalam desikator. Inkubasi dilakukan pada suhu ruang selama $3-7$ hari dan diamati pertumbuhannya.

Teknik pembanding yang digunakan adalah teknik Hungate. Tabung reaksi yang berisi biakan ditutup dengan sumbat karet dan dialiri gas nitrogen menggunakan syringe steril. Inkubasi dilakukan pada suhu ruang selama $3-7$ hari dan diamati pertumbuhannya. Sebagai kontrol positif, tabung reaksi lainnya yang berisi biakan disimpan pada suhu ruang tanpa perlakuan.

\section{b) Isolasi Mikroorganisme}

Sebanyak $10 \mathrm{~mL}$ media thioglikolat dimasukkan ke dalam tabung reaksi dan disterilisasi selama 15 menit pada suhu 121 oC dengan tekanan 1,5 atm. Mikroorganisme yang berasal dari IPAL diinokulasikan ke dalam media tersebut. Biakan tersebut kemudian diletakkan ke dalam desikator yang ditutup rapat dan dialirkan gas nitrogen untuk mengeluarkan gas yang ada di dalam desikator. Biakan diletakkan di tempat gelap dan terang. Inkubasi selama 7 hari.

Tahap Analisis dan Pengembang biakan Mikroorganisme

Mikroorganisme dan isolat pembanding dianalisis dan diamati secara makroskopis, mikroskopis, dan uji pembentukan hidrogen sulfida.

\section{a) Pengamatan makroskopis}

Pengamatan makroskopis dilakukan dengan mengamati pertumbuhan mikroorganisme pada media thioglikolat.

\section{b) Pengamatan mikroskopis}

Pengamatan mikroskopis dilakukan dengan mengamati mikroorganisme secara visual dan membandingkannya dengan literatur menggunakan mikroskop digital Olympus BX-41 pada perbesaran $10 \times 40$ dan $10 \times 100$. Perbedaan susunan dinding sel bakteri gram negatif dan gram positif diamati melalui pewarnaan gram (Fardiaz, 1992). Pengamatan dilakukan dengan mikroskop digital Olympus BX-41 pada perbesaran $10 \mathrm{x}$ 40 dan $10 \times 100$.

\section{c) Uji pembentukan hidrogen sulfida}

Pengujian dilakukan menggunakan medium Triple Sugar Iron Agar (TSIA).

Jarum inokulasi yang mengandung mikroorganisme ditusukkan ke dalam media semi padat TSIA secara aseptis, kemudian diinkubasi selama 24 jam pada suhu $37 \mathrm{oC}$ (Humaidah, 2011).

\section{d) Pengembang biakan mikroorganisme \\ Pengembang biakan mikroorganisme} hasil isolasi dilakukan menggunakan desikator sebagai inkubator anaerobik. 


\section{HASILDAN PEMBAHASAN}

Uji potensi desikator vakum sebagai inkubator anaerob telah dilakukan oleh Humaidah (2011), dimana isolat bakteri obligat an aerob yang digunakan dapat tumbuh, namun isolat bakteri obligat aerob dan fakultatif juga masih tumbuh.

Hasil percobaan secara makroskopis dapat dilihat pada Gambar 1, 2 dan 3.

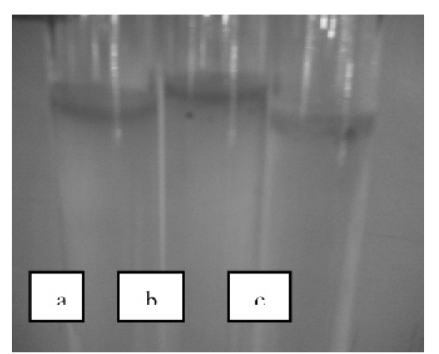

Gambar 1. Hasil uji makroskopis pada P. aeruginosa (a. Pada desikator b. Kontrol positif c.Metoda Hungate)

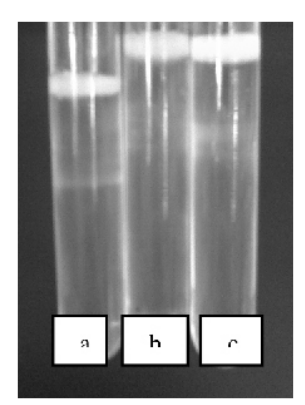

Gambar 2. Hasil uji makroskopis pada E. coli (a. Pada desikator b. Kontrol positif c.Metoda Hungate)
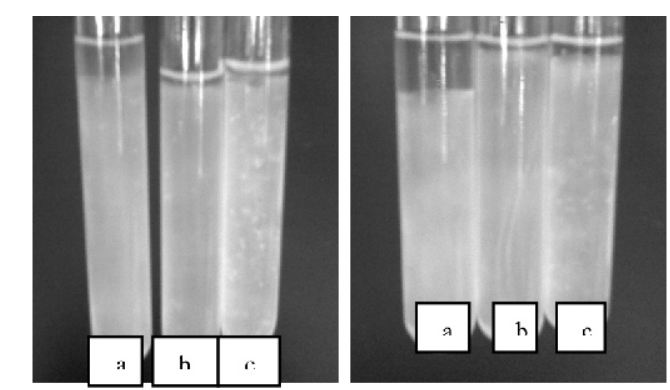

Gambar 3. Hasil uji makroskopis pada D. desulfuricans dan $\mathrm{M}$. ruminantium

(a. Pada desikator b. Kontrol positif c.Metoda Hungate)

Berdasarkan Gambar 1, 2 dan 3 dapat dilihat bahwa isolat P. aeruginosa, E. coli, D. desulfuricans dan Methanobrevibacter ruminantium pada ketiga kondisi masih dapat tumbuh.

Bakteri P. Aeruginosa yang ditumbuhkan pada desikator dan metoda Hungate tumbuh lebih sedikit dibandingkan dengan kontrol positif. Hal ini terlihat dari bercak berwarna hijau kehitaman yang tumbuh di permukaan tabung reaksi. Pertumbuhan ini sesuai dengan sifat bakteri tersebut (obligat aerob) yang akan tumbuh di permukaan tabung reaksi. Hal ini juga sesuai dengan kondisi media thioglikolat dimana pada media ini terdapat indikator rezasurin yang akan menunjukkan warna pink bila terdapat oksigen pada media. Thioglikolat yang ditambahkan pada medium akan memperlihatkan bahwa oksigen akan berada hanya di permukaan yang berdifusi dengan udara (O'flaherty, tanpa tahun). Kondisi ini diperlihatkan pada Gambar 4.

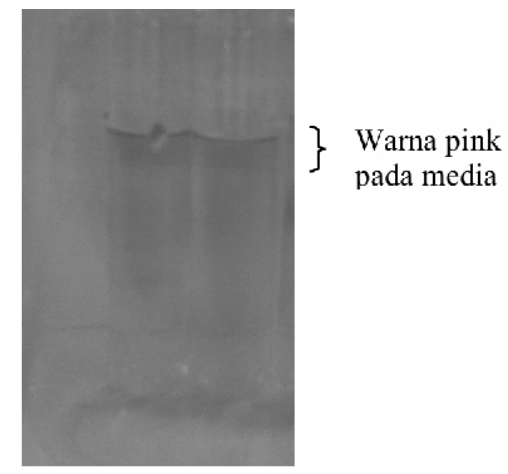

Gambar 4. Medium thioglikolat

Menurut Ortega (2007), bakteri P. Aeruginosa dapat tumbuh pada konsentrasi oksigen $0,4 \%$. Media thioglikolat yang mengandung agar sebanyak $0,075 \%$, akan menghambat difusi oksigen dari permukaan media ke dasar media. Konsentrasi oksigen pada permukaan media yang lebih tinggi (ditunjukkan dengan warna pink) memungkinkan bakteri obligat aerob untuk tumbuh.

Pada Gambar 2 terlihat bahwa bakteri E. coli tumbuh sampai pertengahan media dan pada Gambar 3, terlihat bahwa isolat yang digunakan baik D. desulfuricans maupun $\mathrm{M}$. ruminantium tumbuh di dasar media 
(dibawah batas warna pink).

Pada uji pembentukan gas hidrogen sulfida dapat dilihat bahwa pada bakteri obligat anaerob, baik pada $\mathrm{D}$. desulfuricans maupun M. Ruminantium, media yang digunakan terangkat yang mengindikasikan bahwa telah terbentuk gas pada bakteri tersebut. Hal ini dapat dilihat pada Gambar 5.

Pada isolat yang ditumbuhkan di dalam desikator (a) terlihat bahwa pada isolat D. desulfuricans maupun M. Ruminantium terjadi pembentukan gas yang cepat yang terjadi pada jam ke-41 yang ditandai dengan terangkatnya media dari dasar tabung reaksi. Endapan hitam pada isolat D. Desulfuricans juga nampak sebagai hasil reaksi gas $\mathrm{H} 2 \mathrm{~S}$ dengan Ferrous sulfat. Pada metoda Hungate dan kontrol positif juga terlihat bintik hitam, namun pembentukan gas yang mampu mengangkat media belum terlihat.

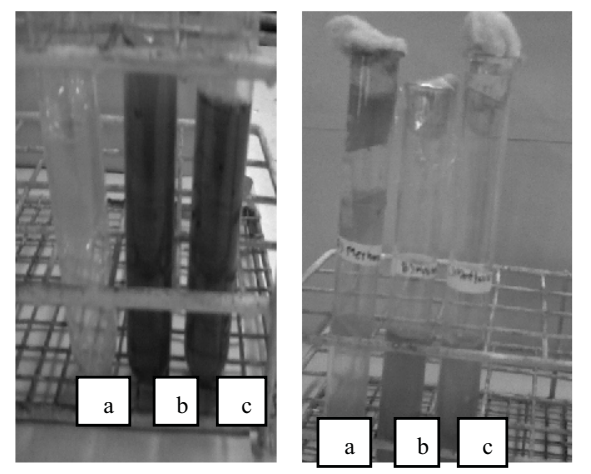

Gambar 5. Hasil uji pembentukan gas H2S pada D. desulfuricans dan M. ruminantium

(a. Pada desikator b. Kontrol positif c. Metoda Hungate)

Pada isolat $M$. ruminantium, media TSIA yang digunakan untuk kontrol positif dan metoda Hungate juga telah berubah warna, namun belum mampu mengangkat media ke permukaan tabung reaksi.

Uji pembentukan gas hidrogen sulfida pada $P$. Aeruginosa dapat dilihat pada Gambar 6.

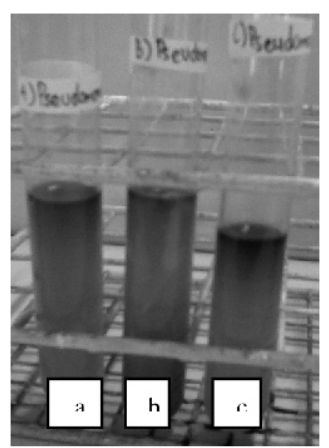

Gambar 6. Hasil uji pembentukan gas H2S pada P. aeruginosa

(a. Pada desikator b. Kontrol positif c. Metoda Hungate)

Hasil uji pembentukan gas $\mathrm{H} 2 \mathrm{~S}$ pada isolat bakteri P. Aeruginosa menunjukkan adanya perubahan warna parsial, dimana sebagian media tetap berwarna merah dan sebagian sudah berubah menjadi kuning. Menurut Harley dan Prescott (2002), bakteri P. Aeruginosa merupakan bakteri yang hanya dapat memfermentasi glukosa, sedangkan laktosa dan sukrosa yang terkandung dalam media TSIA tidak terfermentasikan.

Hasil uji pembentukan gas H2S pada isolat bakteri E. coli dapat dilihat pada Gambar 7

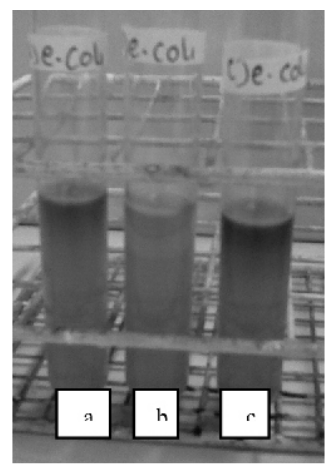

Gambar 7. Hasil uji pembentukan gas $\mathrm{H} 2 \mathrm{~S}$ pada E. coli

(a. Pada desikator b. Kontrol positif c. Metoda Hungate)

Berdasarkan Gambar 7, terlihat bahwa isolat bakteri E.coli masih menunjukkan perubahan warna parsial. Perubahan warna di seluruh bagian media baru terlihat pada kontrol positif. E. coli merupakan bakteri yang mampu memfermentasi laktosa dan 
glukosa, sehingga akan mengakibatkan penurunan $\mathrm{pH}$ yang ditandai dengan perubahan warna menjadi kuning di seluruh bagian media serta menghasilkan gas yang ditandai dengan sedikit terangkatnya bagian bawah media biakan (Harkey dan rescott, 2002).

Hasil uji mikroskopis dilakukan dengan membandingkan hasil pengamatan bakteri secara visual menggunakan mikroskop Olympus BX-41 pada perbesaran 10 x 100 dan 10 x 40 dengan literatur dan melakukan pewarnaan gram.

Bentuk dan pewarnaan gram bakteri Aeruginosa serta perbandingan dengan literatur dapat dilihat pada Gambar 8, sedangkan untuk bakteri E. Coli, D. Desulfu-ricans dan $M$. ruminantium dapat dilihat pada Gambar 9, 10 dan 11. Isolat bakteri P. aeruginosa, E. coli, dan D. desulfuricans merupakan bakteri gram negatif. Hal ini juga nampak pada pengujian pewarnaan gram.

Bakteri dari genus Methanobacterium, Methanobrevibacter, dan Methanospaera termasuk gram positif, suhu pertumbuhan optimum antara 35-450C, pH 5-7, mempunyai endospora dan dapat tumbuh baik dalam asetat. Balch dan Wolfe (1981) juga menyatakan bahwa methanobrevibacter mempunyai bentuk

oval rods atau coccus (short rods), biasanya berbentuk rantai, mempunyai lebar sekitar 0.5-0.7 in dan panjang 0.8-1.4 in, nonspora dan termasuk gram positif. Hasil pengujian isolat bakteri $M$. Ruminantium juga menunjukkan bahwa isolat termasuk bakteri gram positif.

Isolasi mikroba dilakukan dengan melakukan pengenceran dari air limbah keluaran proses pengolahan anaerob di Instalasi Pengolahan Air Limbah sebuah pabrik Tekstil di Leuwigajah Cimahi. Jenis mikroorganisme anaerobik yang dapat diidentifikasi terbatas karena pada lokasi pengambilan cuplikan,tidak tersedia saluran khusus untuk mengambil cuplikan dari granule atau selimut lumpur yang mewakili jenis mikroorganisme dalam reaktor, sehingga cuplikan hanya dapat diambil dari aliran efluen reaktor.

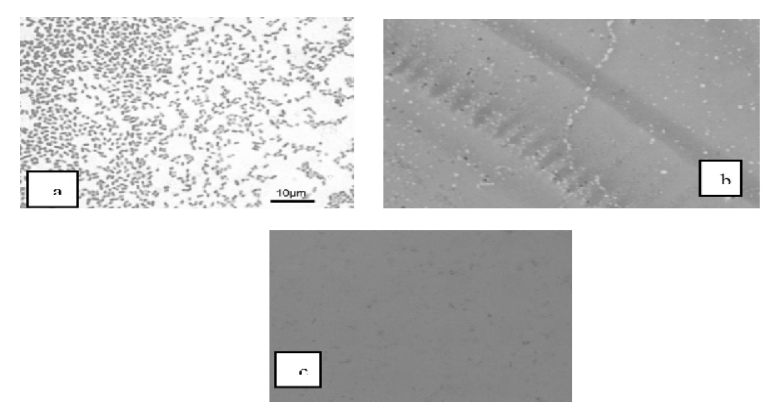

Gambar 8. Bentuk bakteri P. Aeruginosa (a. literatur b. Perbesaran 100 x 10 c. Pewarnaan) Sumber literatur :

Morphological Alterations of Pseudomonas aeruginosa by Ticarcillin: a Scanning Electron Microscope Study (Richard B. Prior and John F. Warner, 1974)

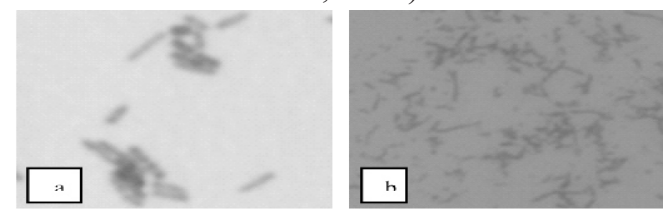

Gambar 9. Hasil pengujian pewarnaan gram pada bakteri E-coli

(a. literatur b. Perbesaran 40 x 10 c. Perbesaran 100 $\mathrm{x} 10)$
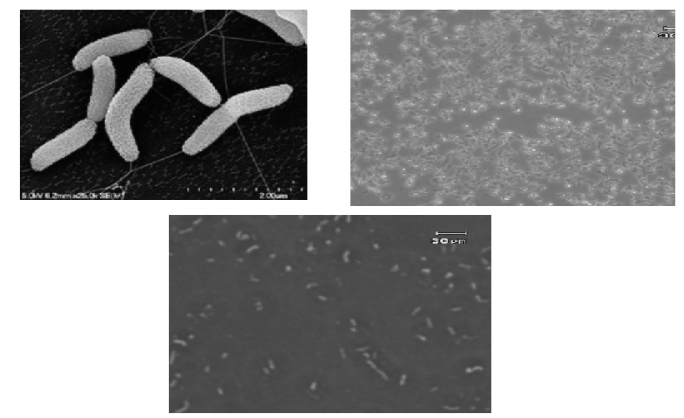

Gambar 10. Bentuk bakteri Desulfovibrio

(a. literatur b. Perbesaran $40 \times 10$

c. Perbesaran 100 x 10)

Sumberliteratur :

www.textbookofbacteriology.net/themicrobialworld/s tructure.html

pada perbesaran 15.000x menggunakan TEM 

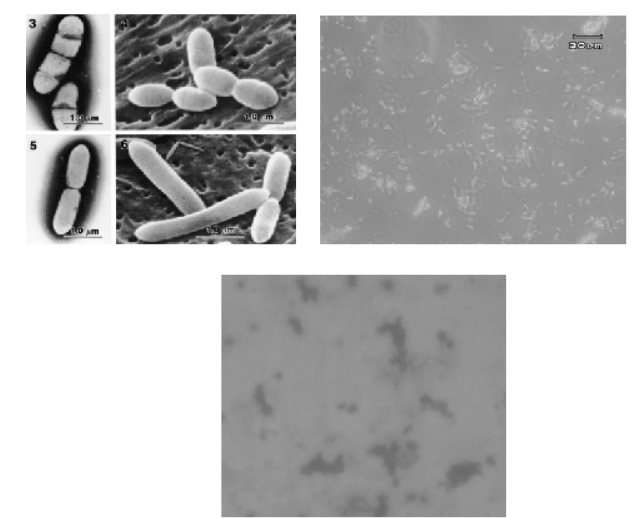

Gambar 11. Bentuk bakteri M. ruminantium (a. literatur (www.springer.com) b. Perbesaran $40 \mathrm{x}$ 10 c. Pewarnaan gram )

Dari hasil pengamatan secara visual, mikroba yang teridentifikasi dalam reaktor anaerob adalah Clostridium, Streptococcae, Methanobacillus, dan Methanococcus. Bakteri yang teridentifikasi ini telah mewakili seluruh tahap yang ada di pengolahan anaerobik. Clostridium adalah bakteri yang berperan dalam proses hidrolisis yang mengurai senyawa organik kompleks, protein dan karbohidrat akan diubah menjadi asam amino dan gula, sedangkan lipid diubah menjadi fatty acid dan alkohol. Streptococcae adalah bakteri yang berperan dalam proses acidogenesis. Methanobacillus dan methanococcus merupakan bakteri yang berperan dalam proses methanogenesis yang menguraikan asam asetat yang telah terbentuk menjadi metana (Metcalf and Eddy, 1991).

Pada penelitian ini, dicoba alternatif untuk melakukan modifikasi terhadap desikator secara sederhana, tanpa menggunakan vakum dan gas. Dicoba untuk menggunakan nyala lilin dalam desikator sebagai indikator keberadaan oksigen. Lilin dinyalakan dan diletakkan dalam desikator yang ditutup rapat. Lilin yang padam menunjukkan habisnya oksigen di dalam desikator.

Hasil penelitian menunjukkan bahwa bakteri an aerob masih dapat tumbuh dalam desikator tersebut (Gambar 12).

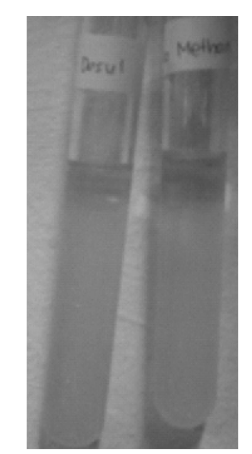

Gambar 12. Bakteri anaerob yang ditumbuhkan dalam desikator dengan indikator nyala lilin

\section{SIMPULAN}

1. Desikator yang dimofifikasi menggunakan gas nitrogen mempunyai efektivitas sebagai inkubator anaerob, dimana bakteri anaerob dapat tumbuh. Pada desikator ini, bakteri obligat aerob dan aerob fakultatif masih dapat tumbuh karena pada media yang digunakan masih terdapat oksigen yang terlarut yang ditandai dengan warna pink di bagian atas media. Desikator yang dimodikasi secara sederhana menggunakan lilin sebagai indikator keberadaan oksigen juga menunjukkan efektivitas untuk digunakan sebagai inkubator anaerob.

2. Hasil isolasi mikroba dari pengolahan limbah anaerob pabrik tekstil diperoleh 6 jenis isolat sehingga diperoleh konsorsium mikroorganisme (mixed culture) anaerobik

\section{DAFTAR RUJUKAN}

Arief, M. L. (2000). Pengolahan Limbah Cair dengan Metode Biologis. Jakarta: Universitas Esa Unggul.

Bagus, I. N. (2008). Start-Up dan Perancangan Bioreaktor Anaerobik Untuk Pengolahan Limbah Cair dengan Konsentrasi Garam Tinggi. Bogor.

Fardiaz, S. (1992). Mikrobiologi Pangan 1. Jakarta: PT Gramedia Pustaka Utama.

Frowen, B. (1992). Anaerobik-Aerobic Treatment of a Dye Wastewater by Combination of RBC with Activated Sludge. 
Gomez, R. R. (2011). Upflow Anaerobik Sludge Blanket Reactor : Modelling. Stockholm: Kungliga Tekniska Hogskolan.

Group, M. E. (t.thn.). Growth Conditions for Strictly Anaerobik Bacteria. Dalam Diversity of Microorganism. Zurich: I n s t i t u t e of P l a n t Biology/Microbiology.

Harley, \& Prescott. (2002). Laboratory Exercise in Microbiology. McGraw Hill.

Humaidah, S. (2011). Potensi Desikator untuk Inkubator Anaerob. Surabaya: Institut Teknologi Sepuluh November.

Kielly, G. (1998). Anaerobik Digestion and Sludge Treatment. Dalam Environmental Engineering (hal. 563573). Singapore: McGraw-Hill International.

Metcalf, \& Eddy. (1991). Anaerobik Suspended-Growth Treatment Processes. Dalam Wastewater
Engineering : Treatment, Disposal and Reuse. Singapore: McGraw Hill International.

Nugraheni, R. (2010). Analisis Mikrobiologis Abon Ikan Tuna dan Kecap. Surakarta: Universitas Sebelas Maret.

O'Flaherty, V. (t.thn.). Anaerobik Culture Techniques. 3rd Science Practical Seminar 1.

Permatasari, I., \& Rafika, Y. (2013). Evaluasi Kinerja Unit Pengolahan Anaerobik di Instalasi Pengolahan Air Limbah PT Garuda Mas Semesta. Bandung: Politeknik Negeri Bandung.

Satrawidana, I. K. (2009). Isolasi Bakteri dari Limbah Tekstil dan Aplikasinya untuk Pengolahan Limbah Tekstil menggunakan Sistem Kombinasi Anaerob-aerob. Bogor: Institut Pertanian Bogor.

Wolfe, R. S. (2011). Techniques for Cultivating Methanogens. Dalam Methods in Enzymology volume 494. Elsevier. 